\title{
Insulin-mediated suppression of lipolysis in adipose tissue and skeletal muscle of obese type 2 diabetic men and men with normal glucose tolerance
}

\author{
Johan W. E. Jocken • Gijs H. Goossens • Hanneke Boon • \\ Rachael R. Mason • Yvonne Essers • Bas Havekes • \\ Matthew J. Watt • Luc J. van Loon • Ellen E. Blaak
}

Received: 18 January 2013 / Accepted: 18 June 2013 / Published online: 2 August 2013

(C) The Author(s) 2013. This article is published with open access at Springerlink.com

\begin{abstract}
Aims/hypothesis Impaired regulation of lipolysis and accumulation of lipid intermediates may contribute to obesityrelated insulin resistance and type 2 diabetes mellitus. We investigated insulin-mediated suppression of lipolysis in abdominal subcutaneous adipose tissue (AT) and skeletal muscle (SM) of obese men with normal glucose tolerance (NGT) and obese type 2 diabetic men.

Methods Eleven NGT men and nine long-term diagnosed type 2 diabetic men ( $7 \pm 1$ years), matched for age ( $58 \pm 2$ vs $62 \pm$ 2 years), BMI ( $31.4 \pm 0.6$ vs $\left.30.5 \pm 0.6 \mathrm{~kg} / \mathrm{m}^{2}\right)$ and $\dot{V} \mathrm{O}_{2 \max }$ $\left(28.9 \pm 1.5\right.$ vs $\left.29.5 \pm 2.4 \mathrm{ml} \mathrm{kg}^{-1} \mathrm{~min}^{-1}\right)$ participated in this study. Interstitial glycerol concentrations in $\mathrm{AT}$ and $\mathrm{SM}$ were
\end{abstract}

Johan W. E. Jocken and Gijs H. Goossens contributed equally to this study.

Electronic supplementary material The online version of this article (doi:10.1007/s00125-013-2995-9) contains peer-reviewed but unedited supplementary material, which is available to authorised users.

J. W. E. Jocken $(\bowtie) \cdot$ G. H. Goossens • Y. Essers • E. E. Blaak Department of Human Biology, NUTRIM School for Nutrition, Toxicology, and Metabolism, Maastricht University Medical Centre $^{+}$, PO Box 616, 6200 MD Maastricht, the Netherlands e-mail: j.jocken@maastrichtuniversity.nl

H. Boon • L. J. van Loon

Department of Human Movement Sciences, NUTRIM School for Nutrition, Toxicology, and Metabolism, Maastricht University Medical Centre ${ }^{+}$, Maastricht, the Netherlands

R. R. Mason • M. J. Watt

Department of Physiology, Monash University, Clayton,

VIC, Australia

B. Havekes

Department of Internal Medicine, Division of Endocrinology,

Maastricht University Medical Centre ${ }^{+}$, Maastricht,

the Netherlands assessed using microdialysis during a $1 \mathrm{~h}$ basal period and a $6 \mathrm{~h}$ stepwise hyperinsulinaemic-euglycaemic clamp $(8,20$ and $\left.40 \mathrm{mU} \mathrm{m}^{-2} \mathrm{~min}^{-1}\right)$. AT and SM biopsies were collected to investigate underlying mechanisms.

Results Hyperinsulinaemia suppressed interstitial SM glycerol concentrations less in men with type 2 diabetes $(-7 \pm 6 \%$, $-13 \pm 9 \%$ and $-27 \pm 9 \%$ ) compared with men with NGT $(-21 \pm 7 \%,-38 \pm 8 \%$ and $-53 \pm 8 \%)(p=0.014)$. This was accompanied by increased circulating fatty acid and glycerol concentrations, a lower glucose infusion rate $(21.8 \pm 3.1 \mathrm{vs}$ $30.5 \pm 2.0 \mu \mathrm{mol} \mathrm{kg}$ body weight $\left.{ }^{-1} \min ^{-1} ; p<0.05\right)$, higher hormone-sensitive lipase (HSL) serine 660 phosphorylation, increased saturated diacylglycerol (DAG) lipid species in the muscle membrane and increased protein kinase $\mathrm{C}$ (PKC) activation in type 2 diabetic men vs men with NGT. No significant differences in insulin-mediated reduction in AT interstitial glycerol were observed between groups.

Conclusions/interpretation Our results suggest that a blunted insulin-mediated suppression of SM lipolysis may promote the accumulation of membrane saturated DAG, aggravating insulin resistance, at least partly mediated by PKC. This may represent an important mechanism involved in the progression of insulin resistance towards type 2 diabetes.

Trial registration: ClinicalTrials.gov NCT01680133

Keywords Adipose tissue - Diabetes · Insulin resistance · Lipolysis · Skeletal muscle

\section{List of abbreviations}

AT Adipose tissue

ATGL Adipose triacylglycerol lipase

DAG Diacylglycerol

GIR Glucose infusion rate 


$\begin{array}{ll}\text { G0S2 } & \text { G0/G1 switch regulatory protein } 2 \\ \text { HSL } & \text { Hormone sensitive lipase } \\ \text { NGT } & \text { Normal glucose tolerance } \\ \text { PKC } & \text { Protein kinase C } \\ \text { PLIN1 } & \text { Perilipin 1 } \\ \text { SM } & \text { Skeletal muscle } \\ \text { TAG } & \text { Triacylglycerol }\end{array}$

\section{Introduction}

Skeletal muscle (SM) lipid accumulation, and more specifically the accumulation of lipid metabolites, is strongly associated with the development of insulin resistance in the obese or obese type 2 diabetic state [1]. There are several bioactive lipid metabolites that may influence muscle insulin sensitivity, including long-chain acyl-CoA [2], ceramides [3, 4] and diacylglycerol (DAG) [5]. Although DAG is only a small fraction of the intramuscular lipid pool, it has potent biological effects and is formed during intracellular lipolysis. DAG is an important second messenger involved in intracellular signalling and may have detrimental effects on insulin action through its ability to activate conventional $\left(\alpha, \beta_{1}, \beta_{2}\right.$, and $\left.\gamma\right)$ and novel $(\delta, \varepsilon, \theta, \eta)$ protein kinase $\mathrm{C}(\mathrm{PKC})$ isoforms in muscle $[6,7]$. On activation, PKCs are redistributed within the cell, such that the membrane-associated kinase is considered to be the active form. Importantly, it seems that cellular localisation and composition of DAG rather than the absolute amount of DAG may be of major importance in insulin resistance [8].

Lipid overflow from adipose tissue (AT) is considered to play a significant role in the development of fat accumulation and insulin resistance [9]. Indeed, the obese insulin-resistant or obese type 2 diabetic state is characterised by increased circulating concentrations of NEFA and/or triacylglycerol (TAG). This increased lipid supply to SM may promote ectopic fat accumulation [10]. Insulin sensitivity of AT lipolysis is normal $[11,12]$ or slightly impaired in obese individuals $[13,14]$. We have previously shown that in long-term diagnosed obese type 2 diabetic men with no compensatory hyperinsulinaemia, the rate of appearance of plasma NEFA is elevated compared with obese men with normal glucose tolerance (NGT) [15]. These data indicate resistance to the antilipolytic effects of insulin, which may significantly contribute to increased circulating NEFA concentrations in this population.

Nevertheless, NEFA generated by intramuscular TAG hydrolysis may also be of importance [16]. We have recently demonstrated intrinsic disturbances in SM lipolysis, including an imbalance of adipose TAG lipase (ATGL) relative to hormone-sensitive lipase (HSL) activity in the obese insulin-resistant state $[17,18]$, contributing to muscle lipid accumulation and the pathogenesis of insulin resistance and type 2 diabetes [19]. The hormonal regulation of SM lipolysis is still not completely elucidated [20,21]. For instance, findings in initial studies that measured interstitial glycerol levels in vivo suggested a lower [21] or higher [20] antilipolytic effect of insulin in SM compared with AT. However, investigations in which the fractional release of glycerol was assessed in situ showed no inhibitory effect of insulin on SM lipolytic activity [21-23].

In the present study, we investigated insulin-mediated suppression of abdominal subcutaneous AT and SM lipolysis during a three-step hyperinsulinaemic-euglycaemic clamp in patients with long-standing type 2 diabetes compared with men with NGT. Careful matching of the type 2 diabetic patients with NGT controls was performed with respect to age, body composition and physical fitness to determine the independent effect of type 2 diabetes (e.g. hyperglycaemia) on insulin-mediated inhibition of tissue lipolysis. AT and SM biopsy analyses were performed to obtain detailed information about gene expression and lipid composition in the cytosolic and muscle membrane fractions of men with type 2 diabetes and NGT.

\section{Methods}

Participants Eleven individuals with NGT and nine with type 2 diabetes matched for age ( $58 \pm 2$ vs $62 \pm 2$ years), BMI $\left(31.4 \pm 0.6\right.$ vs $\left.30.5 \pm 0.6 \mathrm{~kg} / \mathrm{m}^{2}\right)$ and $\dot{V} \mathrm{O}_{2 \max }(28.9 \pm 1.5$ vs $29.5 \pm 2.4 \mathrm{ml} \mathrm{kg}^{-1} \mathrm{~min}^{-1}$ ) participated in the study. Type 2 diabetic participants had been diagnosed for at least 5 years and were not using insulin treatment. Men with NGT had a fasting plasma glucose (FPG) $<6.1 \mathrm{mmol} / 1$ (or $<5.6 \mathrm{mmol} / \mathrm{l}$ where there was a family history of type 2 diabetes) and a $2 \mathrm{~h}$ plasma glucose $<7.8 \mathrm{mmol} / \mathrm{l}$. All participants gave written informed consent. The Medical-Ethical Committee of Maastricht University approved the study protocol.

Study design All participants were asked to refrain from alcohol and strenuous exercise for a period of $48 \mathrm{~h}$ before the study days. Blood-glucose and lipid-lowering medication (metformin $n=4$, simvastatin $n=3$ ) were withdrawn 3 days prior to the study days and participants were asked to maintain their habitual dietary intake throughout the study. Individuals came to the laboratory by car or public transport in the morning after an overnight fast and were in the supine position for the study. Insulin-mediated suppression of lipolysis in the abdominal subcutaneous AT and the gastrocnemius muscle was investigated using microdialysis, as described below. One week after the clamp, abdominal subcutaneous AT and SM biopsies were taken, as described in more detail below. 
Microdialysis On arrival, two microdialysis catheters (CMA 60; CMA Microdialysis, Stockholm, Sweden) were placed in abdominal subcutaneous AT $6-8 \mathrm{~cm}$ to either side of the umbilicus, and two microdialysis probes were placed in the medial part of the gastrocnemius muscle of both legs after local anaesthesia (Xylocaine 2\% without adrenaline [epinephrine]; AstraZeneca, Zoetermeer, the Netherlands) and under sterile conditions. Thereafter, 90 min were allowed for recovery of the tissue from the insertion trauma. After insertion, the two probes were perfused with Ringer solution (Baxter, Utrecht, the Netherlands) at a flow rate of $0.3 \mu \mathrm{l} / \mathrm{min}$ (one in AT and one in SM). Microdialysate was collected from these sites in fractions every $30 \mathrm{~min}$ for the measurement of interstitial glycerol, glucose, lactate and pyruvate concentrations (CMA 600 Microdialysis Analyzer, Pronexus Analytical, Stockholm, Sweden). The two contralateral probes were perfused with Ringer solution supplemented with $50 \mathrm{mmol} / \mathrm{l}$ ethanol at a flow rate of $5.0 \mu \mathrm{l} / \mathrm{min}$. Microdialysate was collected from these sites in fractions every $15 \mathrm{~min}$ to assess the ethanol outflow/inflow ratio as an indicator of local nutritive blood flow [24]. Ethanol concentrations were measured spectrophotometrically at $340 \mathrm{~nm}$ using a standard ethanol assay kit (176290; Boehringer, Mannheim, Germany).

Three-step hyperinsulinaemic-euglycaemic clamp After insertion of the microdialysis probes, two cannulas were inserted. Arterialised blood was obtained through a 20 -gauge cannula inserted retrogradely into a superficial dorsal hand vein. The hand was warmed in a hot box (air circulating at $60^{\circ} \mathrm{C}$ ) to achieve adequate arterialisation [25]. In the contralateral arm, a second cannula was introduced anterogradely in an antecubital vein of the forearm for the infusion of $20 \%$ (wt/vol.) glucose (IVAC560 pump, IVAC, San Diego, CA, USA) and insulin (Actrapid, Novo Nordisk Farma, Alphen aan den Rijn, the Netherlands) using a Harvard pump (Plato, Diemen, the Netherlands). A small amount of blood was drawn from the dorsal hand vein every $5 \mathrm{~min}$ throughout the clamp to determine glucose concentrations (EML 105, Radiometer, Copenhagen, Denmark). After the collection of three baseline samples (at $-30 \mathrm{~min},-15 \mathrm{~min}$ and $0 \mathrm{~min}$ ), a threestep primed hyperinsulinaemic-euglycaemic clamp was started with infusion of 8 (0-120 $\mathrm{min}), 20$ (120-240 $\mathrm{min})$ and $40 \mathrm{mU} \mathrm{m}^{-2} \mathrm{~min}^{-1}$ (240-360 min) insulin. The amount of glucose infused was adjusted to maintain euglycaemia at baseline glucose concentrations $(5.5 \pm 0.1$ vs $8.6 \pm 0.4 \mathrm{mmol} / 1$ in men with NGT and type 2 diabetes, respectively).

Plasma glucose (ABX Pentra Glucose HK CP, Radiometer, Copenhagen, Denmark), NEFA (NEFA C kit, Wako Chemicals, Neuss, Germany) and glycerol (EnzyPlus Glycerol kit, DiffChamp, Västra Frölunda, Sweden) concentrations were determined with commercially available kits using standard enzymatic methods. Plasma insulin concentrations were measured by a specific double-antibody radioimmunoassay for human insulin (Linco Research, St Charles, Missouri, USA).

Abdominal subcutaneous AT and SM biopsies After an overnight fast an abdominal subcutaneous AT biopsy was collected $6-8 \mathrm{~cm}$ lateral from the umbilicus and a vastus lateralis muscle biopsy was obtained under local anaesthesia (Xylocaine) using the Bergström needle biopsy technique [26]. Tissues were snap-frozen in liquid nitrogen and immediately stored at $-80^{\circ} \mathrm{C}$ until further analysis.

Gene-expression analysis Total RNA was extracted from frozen AT and SM specimens, as described before [17, 18]. The expression of genes involved in the lipolytic pathway (ATGL [also known as PNPLA2]; HSL [also known as $L I P E]$; $A B H D 5$, encoding abhydrolase domain containing 5 (ABHD5); G0S2, G0/G1 switch regulatory protein 2 (G0S2); PLIN1 and PLIN2, encoding perilipin 1 (PLIN1) and 2; and AQP7, aquaporin 7), glucose transport (GLUT4 [also known as $S L C 2 A 4]$ ), insulin signalling (IRS1 and IRS2; $P D E 3 B$, phosphodiesterase $3 \mathrm{~B})$, fatty acid transport (CD36, fatty acid translocase), mitochondrial biogenesis ( $P G C 1 \alpha$ [also known as PPARGC1A], peroxisome proliferator-activated receptor $\gamma$, coactivator $1 \alpha$ ), lactate signalling (GPR81 [also known as $H C A R 1]$, G protein-coupled receptor 81 ), and glycerol re-esterification ( $G K$, glycerol kinase) were investigated in both AT and SM. Gene-expression levels were normalised using the housekeeping genes $60 \mathrm{~S}$ ribosomal protein L13a (RPL13A) and $\beta_{2}$-microglobulin (B2M), as GeNorm analysis demonstrated that these housekeeping genes had the highest stability.

Antibodies and western blot analysis A rabbit polyclonal antibody raised against the phosphopeptide based on the amino-acid sequence of murine ATGL (400-414) pS406 LRRAQpSLPSVPLSC (corresponding to human $A T G L$ pS404) was purified as described previously [27, 28]. Furthermore, commercially available primary and secondary antibodies were used as previously described [17, 18]. Muscle tissue was homogenised and resolved by SDSPAGE as described before [17, 18, 28].

Membrane fractionation Membrane and cytosolic fractions were isolated using an ultracentrifugation protocol. Briefly, muscle biopsies were extracted 1:10 (wt/vol.) in ice-cold basic buffer (100 mmol/1 EDTA, $100 \mathrm{mmol} / 1$ EGTA, $1.5 \mathrm{~mol} / 1$ Tris and $\beta$-glycerolphosphate), protease (Roche Applied Science, Indianapolis, IN, USA) and phosphatase inhibitors (Sigma, St Louis, MO, USA) at $4^{\circ} \mathrm{C}$. Homogenates were centrifuged at $160,000 \mathrm{~g}$ for $20 \mathrm{~min}$, and the supernatant fraction, representing the cytosolic fraction, was removed and stored at $-80^{\circ} \mathrm{C}$. The pellet was resuspended in triton-supplemented 
buffer and sonicated. After $1 \mathrm{~h}$ at $4^{\circ} \mathrm{C}$ with constant gentle inversion, the extract was centrifuged at $160,000 \mathrm{~g}$ for $20 \mathrm{~min}$, and the supernatant fraction representing the membrane fraction was saved.

SM lipid composition of cytosolic and membrane fraction Total lipids were extracted from muscle cytosolic and membrane fractions using chloroform-methanol 2:1 (vol.:vol.). The extracted lipids were separated into TAG, DAG, fatty acids and phospholipid by thin-layer chromatography as described before [18].

Statistics Data are presented as means \pm SEM. The overall effect of hyperinsulinaemia on interstitial and circulating metabolite levels over time, between groups and time $\times$ group interaction was analysed using repeated-measures ANOVA. Post hoc testing was performed using Students' unpaired $t$ test with Bonferroni adjustment for multiple testing when ANOVA showed a significant time-over-group effect. Relationships between lipid species, insulin sensitivity and insulin-mediated suppression of lipolysis were calculated using Pearson's correlation coefficient. Calculations were performed using SPSS 18.0 for Mac (Chicago, IL, USA). A value of $p<0.05$ was considered to be statistically significant. Calculation of sample size was performed using GPower (version 3.1 for Mac, Heinrich-Heine University, Düsseldorf, Germany), indicating that nine individuals per group would be sufficient to detect a mean difference in dialysate glycerol concentration of $50 \mu \mathrm{mol} / \mathrm{l}$, with a power of $0.8, \propto 0.05$ and SD $25 \mu \mathrm{mol} / \mathrm{l}$, including an anticipated drop out of $10 \%$ [21].

\section{Results}

Participants Participants' characteristics are shown in Table 1. Men with NGT and type 2 diabetes had comparable age, BMI, body fat percentage, WHR and $\dot{V} \mathrm{O}_{2 \max }$. Type 2 diabetic men had been diagnosed for at least 5 years (average $7 \pm 1$ years) and had well-controlled glucose concentrations. As expected, fasting glucose and $\mathrm{HbA}_{1 \mathrm{c}}$ were significantly higher in the type 2 diabetic group, whereas fasting insulin concentrations were comparable between groups. Insulin sensitivity (HOMA-insulin resistance [IR]), was significantly reduced in the type 2 diabetic group compared with the NGT group.

Circulating metabolite concentrations Plasma insulin concentrations were stable during the steady-state of the clamp and not significantly different between the groups (Fig. 1a). Blood-glucose concentrations were maintained at fasting concentrations throughout the entire clamp in both groups (Fig. 1b). Circulating NEFA and glycerol concentrations were
Table 1 Participants' characteristics

\begin{tabular}{lll}
\hline Characteristic & NGT $(n=11)$ & $\begin{array}{l}\text { Type 2 diabetes } \\
(n=9)\end{array}$ \\
\hline Age (years) & $58 \pm 8$ & $62 \pm 6$ \\
BMI $\left(\mathrm{kg} / \mathrm{m}^{2}\right)$ & $31.4 \pm 1.8$ & $30.5 \pm 2.1$ \\
Body fat $(\%)$ & $30.1 \pm 6.2$ & $31.3 \pm 4.6$ \\
$\mathrm{WHR}$ & $1.04 \pm 0.05$ & $1.05 \pm 0.05$ \\
$\dot{V} \mathrm{O}_{2 \max }\left(\mathrm{ml} \mathrm{min}{ }^{-1} \mathrm{~kg}^{-1}\right)$ & $28.9 \pm 4.8$ & $29.5 \pm 6.7$ \\
$\left.\mathrm{Glucose}^{-1} \mathrm{mmol} / \mathrm{l}\right)$ & $5.5 \pm 0.2$ & $8.6 \pm 1.5^{*}$ \\
Insulin $(\mathrm{pmol} / \mathrm{l})^{\mathrm{HOMA}-\mathrm{IR}}$ & $89 \pm 33$ & $108 \pm 44$ \\
$\mathrm{HbA}(\%)$ & $3.3 \pm 1.2$ & $6.0 \pm 2.8^{*}$ \\
$\mathrm{HbA}(\mathrm{mmol} / \mathrm{mol})$ & $5.6 \pm 0.3$ & $6.9 \pm 0.6$ \\
$\mathrm{AST}(\mu \mathrm{kat} / \mathrm{l})$ & $38.20 \pm 1.07$ & $52.40 \pm 2.19^{*}$ \\
$\mathrm{ALT}(\mu \mathrm{kat} / \mathrm{l})$ & $0.37 \pm 0.15$ & $0.42 \pm 0.17$ \\
\hline
\end{tabular}

Values are means $\pm \mathrm{SD}$

${ }^{*} p<0.05$ men with NGT vs type 2 diabetes, unpaired samples $t$ test ALT, alanine aminotransferase; AST, aspartate aminotransferase

significantly elevated in type 2 diabetic men during the entire $6 \mathrm{~h}$ clamp period (ANOVA group $p<0.01$; Fig. 1c, d).

Interstitial glycerol Interstitial glycerol concentrations in abdominal subcutaneous AT were comparable between groups at baseline (Fig. 2a) and decreased to the same extent during the clamp in both groups (Fig. 2a, b). At the end of step $3\left(40 \mathrm{mU} \mathrm{m}^{-2} \mathrm{~min}^{-1}\right)$, values had decreased by $44 \pm 5 \%$ and $47 \pm 9 \%$ in the AT of men with type 2 diabetes and NGT, respectively (Fig. 2b).

Baseline SM interstitial glycerol concentrations were significantly higher in men with type 2 diabetes compared with NGT $(152 \pm 11$ vs $119 \pm 16 \mu \mathrm{mol} / \mathrm{l} ; p<0.05$, Fig. $2 \mathrm{c})$ and during the $6 \mathrm{~h}$ clamp (ANOVA time $\times$ group $p=0.043$; Fig. $2 \mathrm{c}$; electronic supplementary material [ESM] Table 1). Muscle interstitial glycerol concentrations decreased by $7 \pm 6 \%$, $13 \pm 9 \%$ and $27 \pm 9 \%$ during the subsequent hyperinsulinaemic steps in type 2 diabetic men, while this decrease was more pronounced in men with NGT $(21 \pm 7 \%, 38 \pm 8 \%$ and $53 \pm 8 \%$; ANOVA time $\times$ group $p=0.014$, Fig. $2 d$; ESM Table 1). In line with this, the absolute decrease from baseline in interstitial glycerol concentration during hyperinsulinaemia was blunted in the SM of type 2 diabetic men compared with men with NGT (ANOVA time $\times$ group $p=0.041$ ). Tissue nutritive blood flow, determined using the ethanol outflow/inflow ratio, was unchanged during hyperinsulinaemia in both groups, indicating changes in interstitial glycerol concentrations are not due to alterations in tissue blood flow (ESM Fig. 1).

Glucose infusion rate and interstitial glucose, lactate and pyruvate The blunted insulin-mediated suppression of SM glycerol concentration was accompanied by reduced peripheral 
Fig. 1 Changes in plasma insulin (a), glucose (b), glycerol (c) and NEFA (d) during baseline and the three-step $6 \mathrm{~h}$ hyperinsulinaemic-euglycaemic clamp $\left(8,20,40 \mathrm{mU} \mathrm{m}^{-2} \min ^{-1}\right)$ in 11 obese men with NGT (black squares) compared with nine type 2 diabetic men (white squares). The response was compared using ANOVA. Curves for glucose, free glycerol and NEFA are significantly different between groups, with $p<0.001, p<0.01$ and $p<0.01$, respectively. Values are means \pm SEM. B, baseline
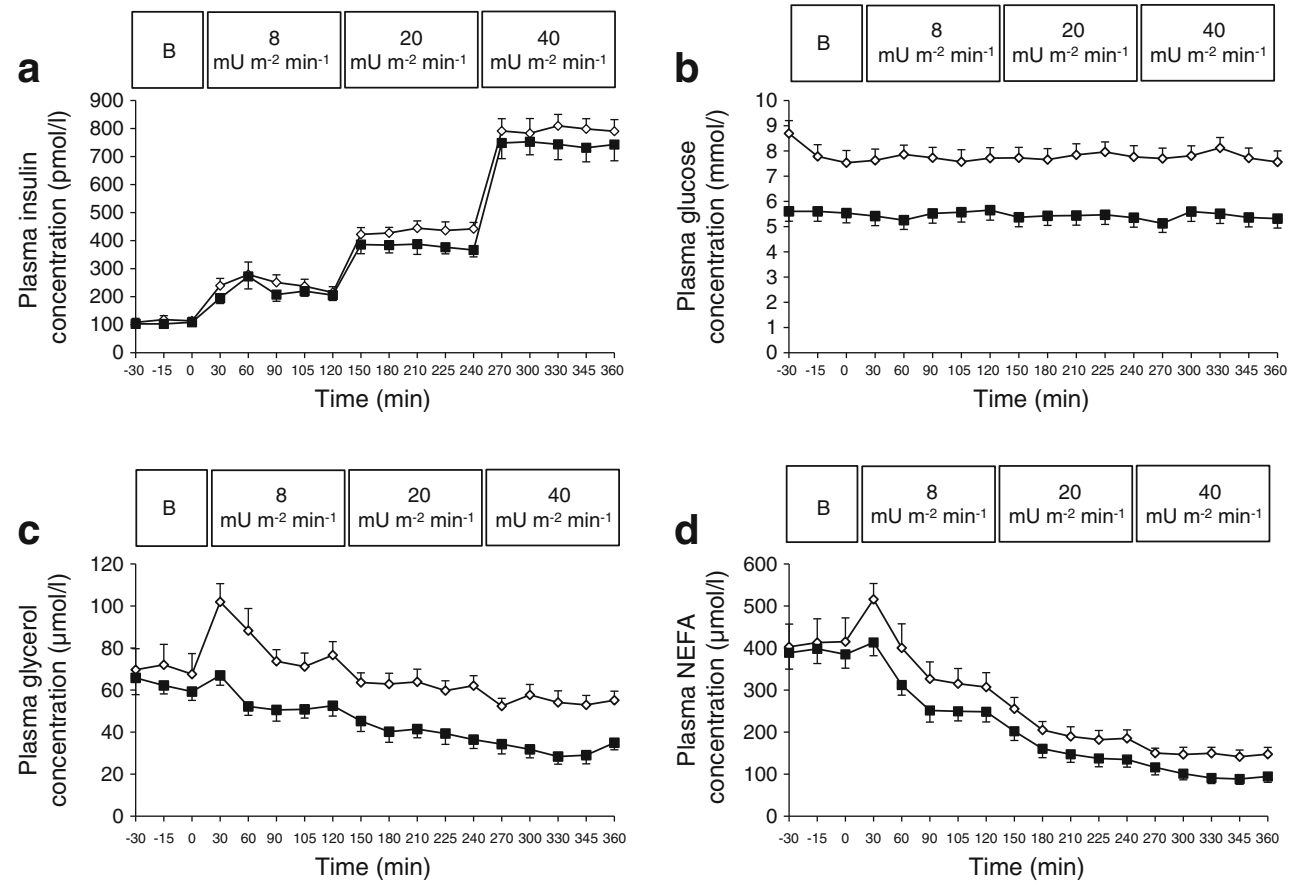

glucose disposal, as indicated by the lower glucose infusion rate (GIR) at $20 \mathrm{mU} \mathrm{m}^{-2} \mathrm{~min}^{-1}(11.6 \pm 0.7 \mathrm{vs} 15.1 \pm 1.1 \mu \mathrm{mol} \mathrm{kg}$ body weight $\left.{ }^{-1} \min ^{-1}, p<0.05\right)$ and $40 \mathrm{mU} \mathrm{m}^{-2} \mathrm{~min}^{-1}$ $\left(21.8 \pm 3.1 \mathrm{vs} 30.5 \pm 2.0 \mu \mathrm{mol} \mathrm{kg}\right.$ body weight ${ }^{-1} \mathrm{~min}^{-1}$, $p<0.05)$ of the clamp in type 2 diabetic men compared with men with NGT (ESM Fig. 2).
Concentrations of SM lactate, a marker of anaerobic metabolism, were significantly elevated at $40 \mathrm{mU} \mathrm{m}^{-2} \mathrm{~min}^{-1}$ during the clamp (ANOVA group $p<0.01$; Fig. $3 \mathrm{e}$ ) in type 2 diabetic men. Interstitial AT and SM glucose concentrations were significantly higher at baseline and during the entire clamp in type 2 diabetic men (ANOVA group $p<0.01$; Fig. 3a, d),
Fig. 2 Interstitial glycerol concentration in subcutaneous AT (a) and SM (c) during baseline and the three-step $6 \mathrm{~h}$ hyperinsulinaemic-euglycaemic clamp $\left(8,20,40 \mathrm{mU} \mathrm{m}{ }^{-2} \mathrm{~min}^{-1}\right)$ in 11 obese men with NGT (black squares) compared with nine type 2 diabetic men (white squares). Changes in interstitial glycerol concentration in subcutaneous AT (b) and SM (d) are expressed as percentage of baseline, calculated using the average from the two baseline measures ( -30 and $0 \mathrm{~min})$. The response was compared using ANOVA. Curves for SM (c and d) showed significant timegroup interaction $(p=0.043$ and $p=0.014$, respectively). Values are means \pm SEM. $B$, baseline
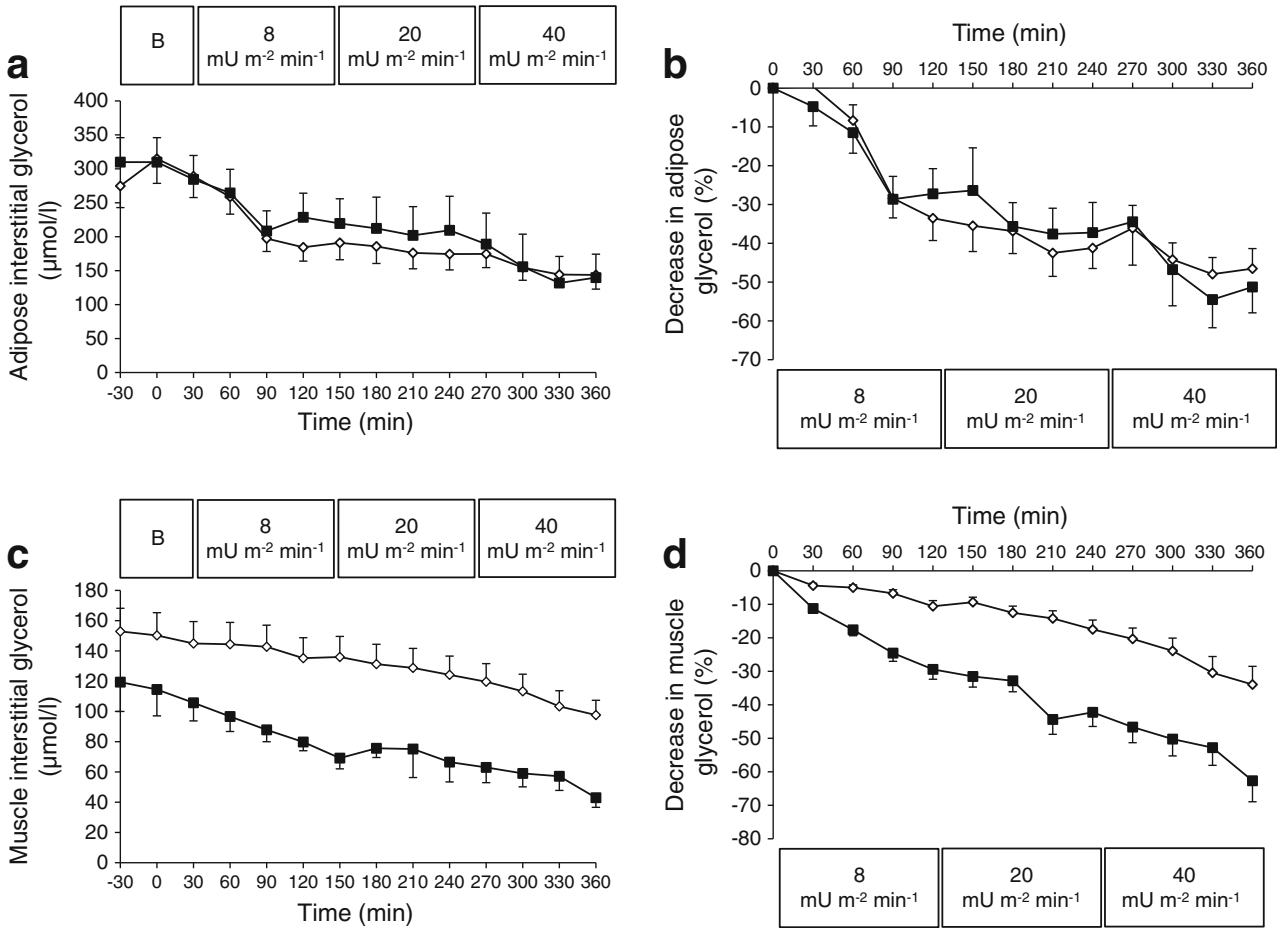
Fig. 3 Interstitial glucose (a, d), lactate $(\mathbf{b}, \mathbf{e})$ and pyruvate concentrations $(\mathbf{c}, \mathbf{f})$ in subcutaneous AT $(\mathbf{a}-\mathbf{c})$ and SM (d-f) during baseline and the three-step $6 \mathrm{~h}$

hyperinsulinaemic-euglycaemic clamp $\left(8,20,40 \mathrm{mU} \mathrm{m}^{-2} \mathrm{~min}^{-1}\right)$ in 11 obese men with NGT (black squares) compared with nine type 2 diabetic men (white squares). The response was compared using ANOVA. AT and SM glucose (a and d) curves and SM lactate (e) curves were significantly different between groups $(p<0.01)$. Values are means \pm SEM. B, baseline
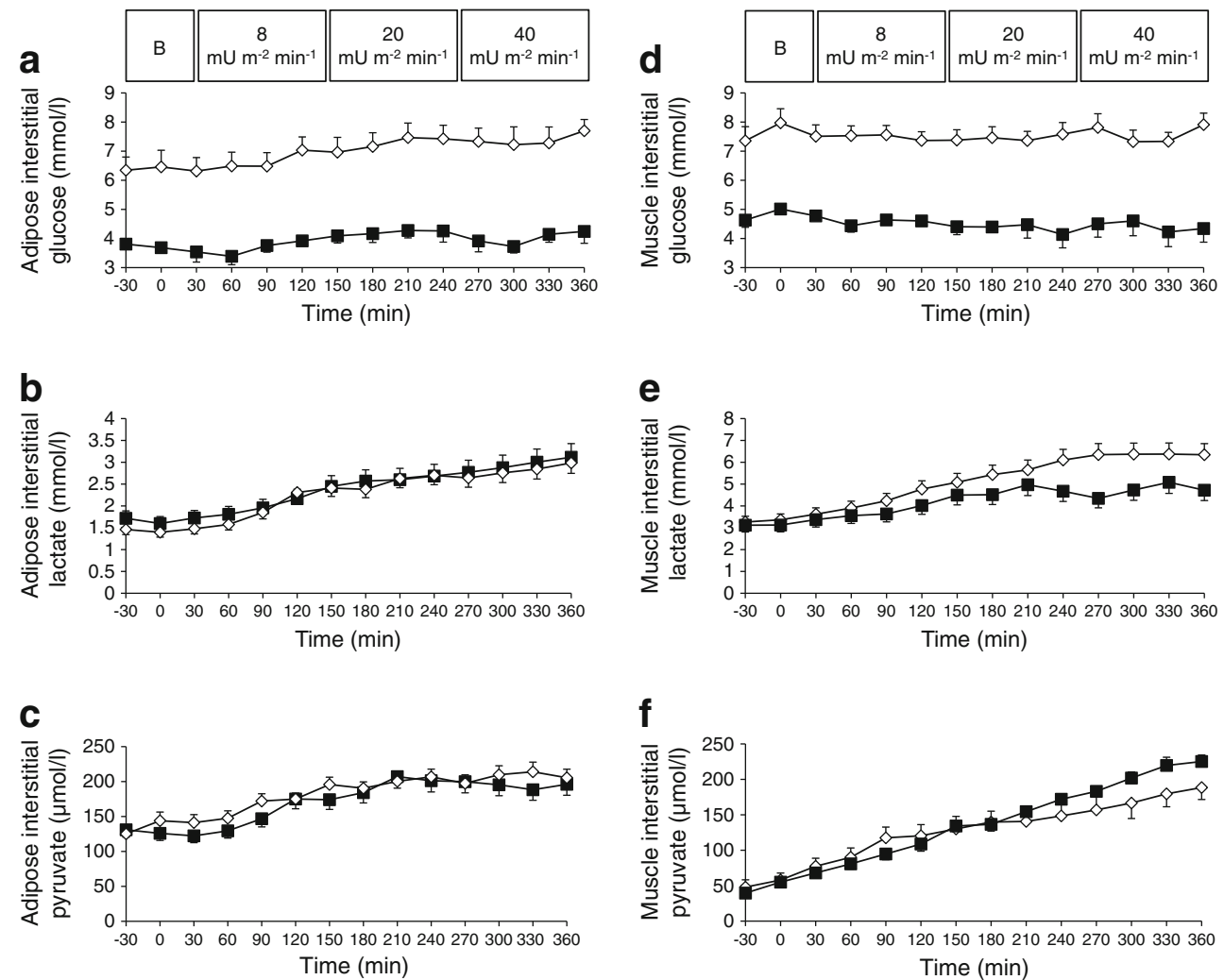

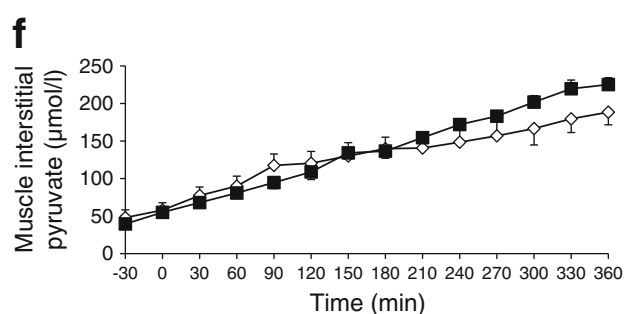

while AT and SM pyruvate concentrations were comparable between groups (Fig. 3c, f).

Gene-expression and protein data As shown in ESM Fig. 3a, $A T G L$ mRNA expression was reduced in the SM of men with type 2 diabetes compared with NGT $(0.70 \pm 0.08$ vs $1.00 \pm 0.10 ; p=0.041)$. The expression of HSL mRNA $(0.68 \pm 0.14$ vs $1.00 \pm 0.16 ; p=0.157)$ and $A B H D 5$ mRNA $(0.85 \pm 0.06$ vs $1.00 \pm 0.07 ; p=0.119)$ was lower in the SM of type 2 diabetic men, though the difference was not statistically significant. Besides disturbances in ATGL expression, reduced GLUT4 mRNA $(0.77 \pm 0.06$ vs $1.00 \pm 0.06$; $p=0.014)$ and a tendency for lower PDE3B mRNA $(0.59 \pm 0.09$ vs $1.00 \pm 0.26 ; p=0.072)$ expression was observed in the SM of type 2 diabetic men. Finally, $P G C 1 \alpha$ mRNA expression was lower in the SM of type 2 diabetic men $(0.72 \pm 0.09$ vs $1.00 \pm 0.06 ; p=0.032)$. No differences in AT gene expression were observed between groups (ESM Fig. 3b).

Muscle ATGL protein content was comparable between groups ( $1.00 \pm 0.12$ vs $0.93 \pm 0.18 ; p=0.737)$ and muscle HSL protein content was significantly lower in type 2 diabetic men $(1.00 \pm 0.31$ vs $0.26 \pm 0.14 ; p=0.037)$. The ratio of phosphorylated ATGL at serine 404 to total ATGL tended to be lower in the SM of men with type 2 diabetes compared with NGT ( $0.78 \pm 0.12$ vs $1.02 \pm 0.09 ; p=0.117$; Fig. $4 \mathrm{a})$, while the ratio of phosphorylated HSL at serine 660 to total HSL was increased in the SM of type 2 diabetic men $(2.63 \pm 0.36$ vs $1.00 \pm 0.19 ; p=0.011 ;$ Fig. $4 \mathrm{~b}$ ). No differences were observed in ABHD5 and G0S2 protein content between groups (Fig. 4c, d). Muscle biopsies were lyophilised and dissected free of extracellular lipid, blood and connective tissue. Additionally, PLIN1 was not detectable in any of the muscle samples, excluding significant contamination by infiltrated adipocytes.

SM lipid composition of cytosolic and membrane fraction Enrichment of membrane (i.e. caveolin 2 [CAV] and immunoglobulin heavy chain-binding protein [BIP]) and cytosolic (i.e. glyceraldehyde-3-phosphate dehydrogenase [GAPDH], ATGL and HSL) markers in their respective subcellular compartments (ESM Fig. 4) show that the cellular fractionation methods were successful and suggest minor contamination between fractions. The cellular distribution of SM lipid species is shown in Table 2. Total SM DAG content was significantly higher in men with type 2 diabetes compared with NGT ( $p=0.022$; Table 2 ). Most DAG was found in the membrane fraction. Interestingly, DAG content was significantly elevated in the SM membrane fraction of type 2 diabetic men compared with men with NGT $(p=0.029$, Table 2). Moreover, the saturated DAG species 16:0, 17:0, 18:0, 22:0 and trans18:1 were more abundant in the SM membrane fraction of men with type 2 diabetes compared with NGT (ESM Table 2). Interestingly, saturated DAG 
Fig. 4 SM ATGL serine 404 phosphorylation (a), HSL serine 660 phosphorylation (b), ABHD5 (c) and G0S2 (d) protein content in men with NGT vs type 2 diabetic men. Protein levels are normalised to men with NGT and differences in loading are corrected by $\alpha$-actin. PLIN1 protein was not detectable in any of the muscle samples excluding significant contamination by infiltrated adipocytes. Values are means \pm SEM and significance was tested using the unpaired $t$ test. ${ }^{\dagger} p=0.117$ and ${ }^{\star} p=0.011$. T2D, type 2 diabetes
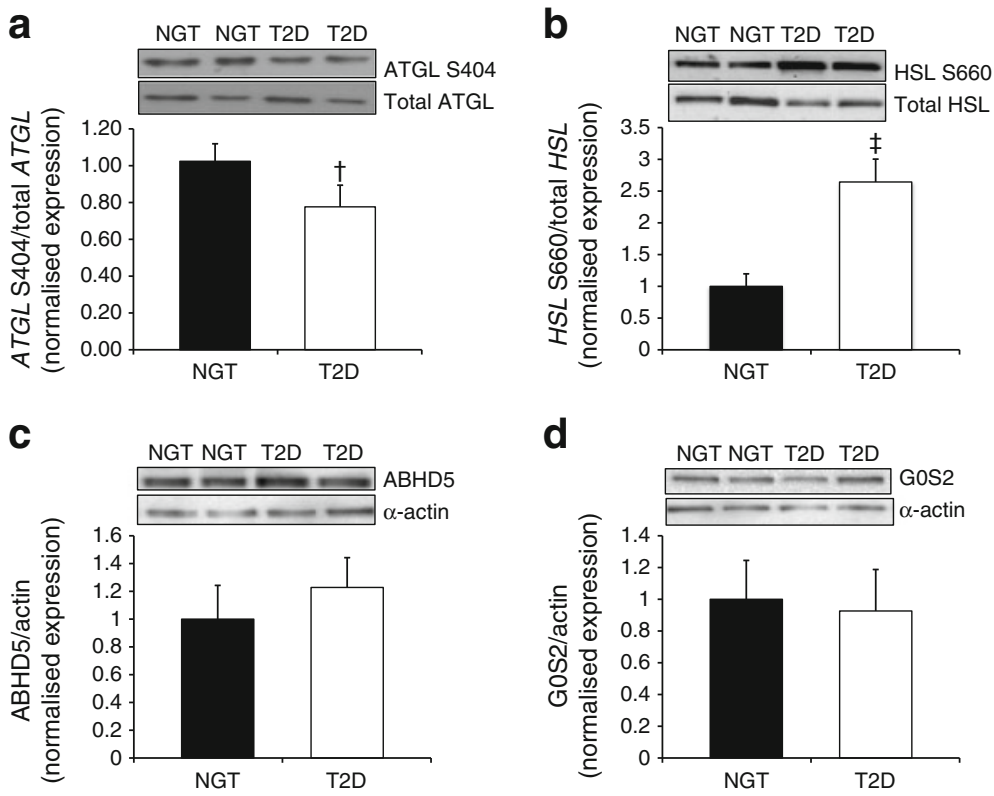

content in the SM membrane showed a strong inverse association with insulin sensitivity (GIR: $r=-0.568, p<0.01$; Fig. 5a) and the decrease in interstitial muscle glycerol $(r=-0.546, p<0.01$; Fig. 5b). Moreover, the increase in membrane saturated DAG was positively associated with PKC activation ( $r=0.376, p<0.01$; Fig. $5 c$ ) (ratio of PKC $\delta$ membrane to cytosolic in men with type 2 diabetes vs NGT: $6.07 \pm 1.19$ vs $2.43 \pm 0.69 ; p=0.028$; ESM Fig. 5). Cytosolic DAG concentration showed no relationship with insulin sensitivity or the decrease in interstitial muscle glycerol. No differences were observed in total or subcellular TAG, phospholipid or fatty acid fractions between groups.

Table 2 Muscle lipid composition in cytosolic and membrane fractions

\begin{tabular}{|c|c|c|c|c|c|c|c|c|}
\hline \multirow[t]{2}{*}{ Lipid } & \multicolumn{2}{|c|}{ TAG ( $\mu \mathrm{mol} / \mathrm{mg}$ protein $)$} & \multicolumn{2}{|c|}{ DAG ( $\mu \mathrm{mol} / \mathrm{mg}$ protein) } & \multicolumn{2}{|c|}{ PL ( $\mu \mathrm{mol} / \mathrm{mg}$ protein) } & \multicolumn{2}{|c|}{$\mathrm{FA}(\mu \mathrm{mol} / \mathrm{mg}$ protein $)$} \\
\hline & NGT & Type 2 diabetes & NGT & Type 2 diabetes & NGT & Type 2 diabetes & NGT & Type 2 diabetes \\
\hline \multicolumn{9}{|l|}{ SFA } \\
\hline Cyto & $4.91 \pm 0.84$ & $4.67 \pm 2.91$ & $14.17 \pm 16.26$ & $19.35 \pm 11.05$ & $4.68 \pm 5.91$ & $4.96 \pm 3.35$ & $0.56 \pm 0.38$ & $0.95 \pm 0.81$ \\
\hline Mem & $272 \pm 157$ & $261 \pm 169$ & $55 \pm 31$ & $102 \pm 51^{*}$ & $250 \pm 63$ & $231 \pm 45$ & $19.86 \pm 9.37$ & $18.37 \pm 5.26$ \\
\hline \multicolumn{9}{|l|}{ MUFA } \\
\hline Cyto & $3.39 \pm 1.78$ & $4.54 \pm 2.87$ & $1.45 \pm 0.96$ & $2.29 \pm 1.92$ & $0.99 \pm 1.18$ & $1.12 \pm 0.61$ & $0.19 \pm 0.16$ & $0.31 \pm 0.16$ \\
\hline Mem & $340 \pm 270$ & $284 \pm 181$ & $48 \pm 20$ & $52 \pm 20$ & $60 \pm 16$ & $74 \pm 31$ & $6.88 \pm 4.65$ & $5.83 \pm 2.78$ \\
\hline \multicolumn{9}{|l|}{ PUFA } \\
\hline Cyto & $1.04 \pm 0.73$ & $1.86 \pm 1.80$ & $2.94 \pm 3.56$ & $3.69 \pm 3.23$ & $2.72 \pm 4.06$ & $1.83 \pm 1.04$ & $0.52 \pm 0.84$ & $0.39 \pm 0.37$ \\
\hline Mem & $112 \pm 85$ & $73 \pm 42$ & $19.50 \pm 12.53$ & $19.39 \pm 9.41$ & $305 \pm 87$ & $252 \pm 61$ & $11.98 \pm 12.58$ & $7.05 \pm 4.28$ \\
\hline \multicolumn{9}{|l|}{ Trans } \\
\hline Cyto & $0.23 \pm 0.08$ & $0.39 \pm 0.46$ & $0.98 \pm 1.18$ & $1.52 \pm 1.86$ & $0.17 \pm 0.28$ & $0.19 \pm 0.25$ & $0.16 \pm 0.21$ & $0.18 \pm 0.25$ \\
\hline Mem & $11.67 \pm 14.75$ & $7.97 \pm 3.21$ & $1.44 \pm 0.99$ & $7.95 \pm 6.39^{*}$ & $4.56 \pm 0.96$ & $4.58 \pm 2.01$ & $0.72 \pm 0.39$ & $0.74 \pm 1.16$ \\
\hline \multicolumn{9}{|l|}{ Total } \\
\hline Cyto & $9.58 \pm 2.27$ & $11.47 \pm 7.32$ & $19.54 \pm 19.79$ & $26.84 \pm 13.27$ & $8.57 \pm 11.29$ & $8.10 \pm 4.17$ & $1.43 \pm 1.14$ & $1.84 \pm 0.93$ \\
\hline Mem & $736 \pm 522$ & $627 \pm 387$ & $124 \pm 40$ & $182 \pm 73^{*}$ & $620 \pm 163$ & $562 \pm 117$ & $41 \pm 26$ & $30 \pm 8$ \\
\hline Total & $745 \pm 520$ & $638 \pm 388$ & $142 \pm 45$ & $209 \pm 77^{*}$ & $628 \pm 164$ & $569 \pm 116$ & $42 \pm 26$ & $32 \pm 8$ \\
\hline
\end{tabular}

Values are means $\pm \mathrm{SD}$

${ }^{*} p<0.05$ men with NGT vs type 2 diabetes, unpaired samples $t$ test

Cyto, cytosolic fraction; FA, fatty acid; Mem, membrane fraction; MUFA, monounsaturated fatty acid; PL, phospholipids; PUFA, polyunsaturated fatty acid; SFA, saturated fatty acid; Trans, trans fatty acid 
a

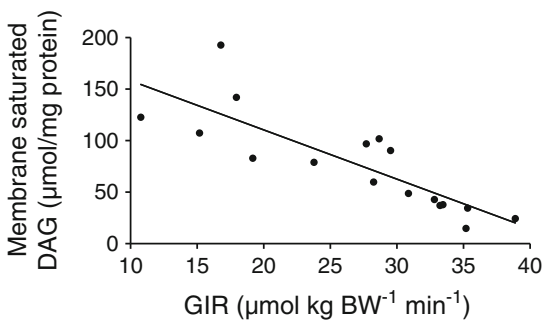

Fig. 5 Relationship between saturated DAG content in the muscle membrane and: GIR $(r=-0.568, p<0.01)(a)$; the percentage decrease in interstitial muscle glycerol concentration $(r=-0.546, p<0.01)(\mathbf{b})$ in
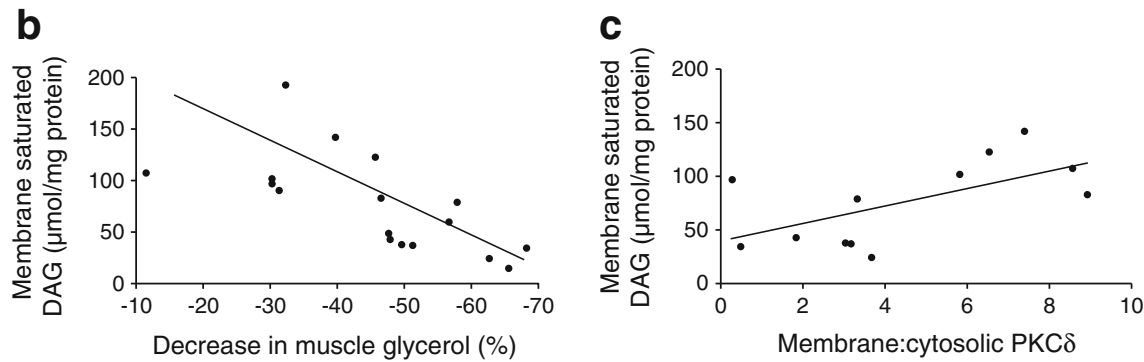

NGT $(n=8)$ and type 2 diabetic $(n=9)$ men; and the ratio of PKC $\delta$ in the membrane to PKC $\delta$ in the cytosolic muscle fraction $(r=0.376, p<0.01)$ in men with NGT $(n=6)$ and type 2 diabetes $(n=6)(\mathbf{c})$

\section{Discussion}

To our knowledge, the present study is the first to examine insulin resistance of abdominal subcutaneous AT and SM lipolysis in long-term-diagnosed obese type 2 diabetic men compared with men with NGT, matched for age, body composition and physical fitness. The main finding of the present study is that long-term diagnosed type 2 diabetic men demonstrated a blunted insulin-induced decrease in muscle lipolysis and higher saturated DAG content in the SM membrane fraction. Moreover, the membrane content of saturated DAG was inversely associated with insulin sensitivity and the insulin-mediated decrease in interstitial SM glycerol concentration. No differences in the insulin sensitivity of AT lipolysis were found.

Previous studies have yielded conflicting data regarding sensitivity to the antilipolytic effects of insulin in abdominal subcutaneous AT and SM. Insulin sensitivity of SM lipolysis has been suggested to be lower [21] or higher [20] compared with subcutaneous AT [20]. Moreover, it has been suggested that SM lipolysis is primarily regulated by substrate supply and is, to a lesser degree, under hormonal control [29]. This concept of differential regulation of AT and SM lipolysis is supported by the presence of different phosphodiesterase and adrenoceptor subtypes in these tissues [30,31]. Our data suggest a clear antilipolytic effect of insulin in both the abdominal subcutaneous AT and SM of obese men with NGT. The relative decreases in AT $(\approx-47 \%)$ and $\mathrm{SM}(\approx-53 \%)$ lipolysis were comparable in men with NGT, indicating tight insulin-mediated regulation of AT and SM lipolysis in men with NGT. This may contribute to an adequate switch between fatty acid and glucose substrate use under postprandial conditions and is of importance for the maintenance of normal glucose tolerance.

In contrast, type 2 diabetic men showed differential regulation of AT and SM lipolysis with increased fasting interstitial glycerol concentrations and a blunted decrease $(\approx-27 \%)$ in muscle interstitial glycerol during hyperinsulinaemia $\left(40 \mathrm{mU} \mathrm{m}^{-2} \mathrm{~min}^{-1}\right)$. Additionally, muscle lactate concentrations were increased in type 2 diabetic muscle, indicative of an increased glycolytic flux during hyperinsulinaemic conditions. This is the first study showing an impaired muscle lipolysis during hyperinsulinaemia in type 2 diabetic men, which may be associated with the accumulation of lipid metabolites and impaired insulin sensitivity, as discussed further below. AT glycerol concentrations were comparable between men with type 2 diabetes and NGT during both baseline and hyperinsulinaemic conditions. Data on the insulin sensitivity of abdominal subcutaneous AT in obese or type 2 diabetic participants are not consistent $[12,13,22,32-35]$. This discrepancy remains to be elucidated but differences between AT depots (e.g. upper vs lower body and subcutaneous vs visceral) in the ability of insulin to suppress fatty acid release may possibly contribute to this [36]. Therefore, there is an urgent need to investigate other AT depots with respect to insulin resistance of systemic fatty acid release.

Baseline mRNA expression of $A T G L$ and $H S L$ and HSL protein content were reduced in type 2 diabetic muscle. Nevertheless, our data show that despite a fourfold lower total HSL protein content in muscle of type 2 diabetic men, total HSL serine 660 phosphorylation and the ratio of phosphorylated HSL serine 660 to total HSL was significantly higher at baseline in type 2 diabetic men compared with controls. This increased phosphorylation might reflect increased HSL activity, possibly explaining the reduced suppression of lipolysis at baseline in muscle of type 2 diabetic men (reflected by increased interstitial glycerol concentrations). Nevertheless, lipolytic regulation is complex and the regulation of lipolysis under hyperinsulinaemic conditions is governed by different mechanisms than under basal fasting conditions. Therefore, it remains to be determined whether increased HSL activity is responsible for the blunted insulinmediated suppression of lipolysis in the muscle of type 2 diabetic men.

ATGL protein content was comparable between groups, while in previous studies increased ATGL protein content has been reported in type 2 diabetic muscle $[18,19]$. In the present study, in contrast to previous studies, type 2 diabetic men and NGT controls were matched not only for age and BMI but also for aerobic capacity $\left(\dot{V} \mathrm{O}_{2 \max }\right)$. Given the fact 
that muscle ATGL activity might produce lipid ligands regulating mitochondrial function via PPAR $\alpha$ target genes [37], matching for aerobic capacity might explain the discrepancy with previous studies [18, 19]. Furthermore, our study is the first to show that ATGL serine 404 phosphorylation tends to be lower in muscle of type 2 diabetic men. The contribution of ATGL phosphorylation to intracellular lipid accumulation and the development of insulin resistance and type 2 diabetes needs to be investigated in future research.

Given the fact that ATGL and HSL are responsible for more than $95 \%$ of the TAG hydrolase activity [38], impaired intracellular lipolysis may have major effects on the accumulation of cellular lipids, in particular DAG, which could interfere with insulin-mediated signal transduction. There are three distinct DAG isomers ( $s n-1,3 ; s n-2,3$; and $s n-1,2$ DAG). To date, only $s n-1,2$ DAG has been associated with insulin signalling and PKC activation [39, 40]. However, both ATGL and HSL lack the ability to generate 1,2-DAG in vitro and it remains to be determined whether lipid droplet-derived DAG may translocate to the membrane and activate PKC [41].

At present, it is unknown whether stereoselectivity of ATGL and HSL is impaired under insulin-resistant conditions. Here, we show for the first time that blunted insulin-mediated inhibition of SM lipolysis is positively associated with membrane DAG in type 2 diabetic men. The relationship was particularly strong with the amount of saturated 16:0 and 18:0 DAG in the muscle membrane. These data strengthen previous observations from our group and others that, in particular, saturated DAG has a negative impact on insulin sensitivity $[42,43]$ and that increased membrane localisation may mediate this relationship [8]. Furthermore, the proportion of PKC $\delta$ in the muscle membrane was increased in type 2 diabetic men and the saturated DAG content of the membrane was positively associated with PKC activation, as shown previously [5]. Several reports in the literature suggest that saturated DAGs are related to PKC activation [42, 44]. However, several other PKC isoforms might be involved in the relationship between membrane DAG and insulin sensitivity. Together, our data indicate that a lipolytic imbalance may promote saturated DAG accumulation in the muscle membrane and worsen insulin resistance (i.e. glucose disposal), at least in part through a PKC-dependent pathway, as has been suggested recently in vitro in human primary myotubes [19].

Some limitations of our study need to be addressed. Interstitial glycerol was used as a measure of lipolysis. There are indications from our laboratory that AT and SM may take up glycerol $[17,45]$ and may exhibit significant glycerol kinase activity [46]. This suggests that interstitial glycerol may not reflect the overall rate of lipolysis, but may instead be the net result of TAG and glycerol metabolism in the tissue and thus reflect glycerol turnover [21]. However, this seems unlikely, as SM $G K$ mRNA expression was comparable between groups (ESM Fig. 3a). A second consideration is that there is evidence for an active transport system of insulin across the blood-tissue barrier, such that insulin concentrations in the interstitium of AT and SM are approximately $50 \%$ of those in plasma $[47,48]$. Although a delayed transcapillary transport of insulin to muscle interstitial fluid has been observed in obese compared with lean men [49], this has not been observed in muscle of type 2 diabetic men compared with healthy age- and BMI-matched controls [50]. Nevertheless, we cannot exclude that the impaired insulin-mediated lipolysis in type 2 diabetic muscle is, in part, the result of reduced interstitial insulin concentrations. Third, the muscle membrane fraction was not only composed of plasma membranes but contained other membranes, including mitochondrial and ER, as indicated by the expression of the ER-marker BIP in the membrane fraction (ESM Fig. 4). As TAG is synthesised and packed in lipid droplets at the ER, this might explain the large amount of TAG in the crude membrane fraction.

Taken together, this is the first report of a blunted insulinmediated suppression of SM lipolysis in long-term-diagnosed obese type 2 diabetic men compared with well-matched men with NGT. The impaired antilipolytic effect of insulin in skeletal muscle was accompanied by excessive accumulation of saturated DAG in the SM membrane and reduced glucose disposal. Together, our data highlight the importance of saturated DAG in the membrane as a potential mechanism involved in the progression of insulin resistance in type 2 diabetic men. Therefore, nutritional and pharmacological approaches to decrease the degree of saturation of membrane DAG composition might promote insulin sensitivity in humans.

Acknowledgements The authors gratefully thank all volunteers for their time and motivation, and Guy Vijgen, Tineke van de Weijer, Jos Stegen, Hasibe Aydeniz and Wendy Sluijsmans (Department of Human Biology, Maastricht University, the Netherlands) for their excellent technical support.

Funding This work was supported by a VENI grant (016.116.074) from the Netherlands Organisation for Scientific Research (NWO) to JWEJ and a clinical research grant from the European Foundation for the Study of Diabetes (EFSD) to EEB and JWEJ. MJW is supported by research grants from the National Health and Medical Research Council of Australia.

Duality of interest The authors declare that there is no duality of interest associated with this manuscript.

Contribution statement All clinical studies were performed and samples were obtained in the laboratory of EEB and analytical experiments were conducted at the laboratories of EEB and MJW. All authors made substantial contributions to the concept and design, acquisition of data or analysis and interpretation of data and to drafting of the article and revising it critically for intellectual content. All authors gave final approval of the version to be published.

Open Access This article is distributed under the terms of the Creative Commons Attribution Noncommercial License which permits any noncommercial use, distribution, and reproduction in any medium, provided the original author(s) and the source are credited. 


\section{References}

1. Coen PM, Goodpaster BH (2012) Role of intramyocellular lipids in human health. Trends Endocrinol Metab 23:391-398

2. Houmard JA, Tanner CJ, Yu C et al (2002) Effect of weight loss on insulin sensitivity and intramuscular long-chain fatty acyl-CoAs in morbidly obese subjects. Diabetes 51:2959-2963

3. Holland WL, Brozinick JT, Wang LP et al (2007) Inhibition of ceramide synthesis ameliorates glucocorticoid-, saturated-fat-, and obesity-induced insulin resistance. Cell Metab 5:167-179

4. Coen PM, Dube JJ, Amati F et al (2010) Insulin resistance is associated with higher intramyocellular triglycerides in type I but not type II myocytes concomitant with higher ceramide content. Diabetes 59:80-88

5. Itani SI, Ruderman NB, Schmieder F, Boden G (2002) Lipidinduced insulin resistance in human muscle is associated with changes in diacylglycerol, protein kinase $\mathrm{C}$, and IkappaB-alpha. Diabetes 51:2005-2011

6. Itani SI, Zhou Q, Pories WJ, MacDonald KG, Dohm GL (2000) Involvement of protein kinase $\mathrm{C}$ in human skeletal muscle insulin resistance and obesity. Diabetes 49:1353-1358

7. Schmitz-Peiffer C, Browne CL, Oakes ND et al (1997) Alterations in the expression and cellular localization of protein kinase $\mathrm{C}$ isozymes epsilon and theta are associated with insulin resistance in skeletal muscle of the high-fat-fed rat. Diabetes 46:169-178

8. Bergman BC, Hunerdosse DM, Kerege A, Playdon MC, Perreault L (2012) Localisation and composition of skeletal muscle diacylglycerol predicts insulin resistance in humans. Diabetologia 55:1140-1150

9. Goossens GH (2008) The role of adipose tissue dysfunction in the pathogenesis of obesity-related insulin resistance. Physiol Behav 94:206-218

10. Karpe F, Dickmann JR, Frayn KN (2011) Fatty acids, obesity, and insulin resistance: time for a reevaluation. Diabetes 60:2441-2449

11. Jansson PA, Larsson A, Smith U, Lonnroth P (1992) Glycerol production in subcutaneous adipose tissue in lean and obese humans. J Clin Invest 89:1610-1617

12. Robinson C, Tamborlane WV, Maggs DG et al (1998) Effect of insulin on glycerol production in obese adolescents. Am J Physiol 274:E737-E743

13. Nellemann B, Gormsen LC, Sorensen LP, Christiansen JS, Nielsen S (2012) Impaired insulin-mediated antilipolysis and lactate release in adipose tissue of upper-body obese women. Obesity (Silver Spring) 20:57-64

14. Ormsbee MJ, Choi MD, Medlin JK et al (2009) Regulation of fat metabolism during resistance exercise in sedentary lean and obese men. J Appl Physiol 106:1529-1537

15. Boon H, Blaak EE, Saris WH, Keizer HA, Wagenmakers AJ, van Loon LJ (2007) Substrate source utilisation in long-term diagnosed type 2 diabetes patients at rest, and during exercise and subsequent recovery. Diabetologia 50:103-112

16. Jocken JW, Blaak EE (2008) Catecholamine-induced lipolysis in adipose tissue and skeletal muscle in obesity. Physiol Behav 94:219-230

17. Jocken JW, Roepstorff C, Goossens GH et al (2008) Hormonesensitive lipase serine phosphorylation and glycerol exchange across skeletal muscle in lean and obese subjects: effect of betaadrenergic stimulation. Diabetes 57:1834-1841

18. Jocken JW, Moro C, Goossens GH et al (2010) Skeletal muscle lipase content and activity in obesity and type 2 diabetes. J Clin Endocrinol Metab 95:5449-5453

19. Badin PM, Louche K, Mairal A et al (2011) Altered skeletal muscle lipase expression and activity contribute to insulin resistance in humans. Diabetes 60:1734-1742
20. Stumvoll M, Jacob S, Wahl HG et al (2000) Suppression of systemic, intramuscular, and subcutaneous adipose tissue lipolysis by insulin in humans. J Clin Endocrinol Metab 85:3740-3745

21. Sjostrand M, Gudbjornsdottir S, Holmang A, Strindberg L, Ekberg K, Lonnroth P (2002) Measurements of interstitial muscle glycerol in normal and insulin-resistant subjects. J Clin Endocrinol Metab 87:2206-2211

22. Bolinder J, Kerckhoffs DA, Moberg E, Hagstrom-Toft E, Arner P (2000) Rates of skeletal muscle and adipose tissue glycerol release in nonobese and obese subjects. Diabetes 49:797-802

23. Moberg E, Sjoberg S, Hagstrom-Toft E, Bolinder J (2002) No apparent suppression by insulin of in vivo skeletal muscle lipolysis in nonobese women. Am J Physiol Endocrinol Metab 283:E295-E301

24. Goossens GH, Blaak EE, Saris WH, van Baak MA (2004) Angiotensin II-induced effects on adipose and skeletal muscle tissue blood flow and lipolysis in normal-weight and obese subjects. J Clin Endocrinol Metab 89:2690-2696

25. Abumrad NN, Rabin D, Diamond MP, Lacy WW (1981) Use of a heated superficial hand vein as an alternative site for the measurement of amino acid concentrations and for the study of glucose and alanine kinetics in man. Metabolism 30:936-940

26. Bergstrom J, Hultman E (1967) Synthesis of muscle glycogen in man after glucose and fructose infusion. Acta Med Scand 182:93-107

27. Chen ZP, Mitchelhill KI, Michell BJ et al (1999) AMP-activated protein kinase phosphorylation of endothelial NO synthase. FEBS Lett 443:285-289

28. Mason RR, Meex RC, Lee-Young R, Canny BJ, Watt MJ (2012) Phosphorylation of adipose triglyceride lipase Ser404 is not related to 5'-AMPK activation during moderate-intensity exercise in humans. Am J Physiol Endocrinol Metab 303:E534-E541

29. Wicklmayr M, Dietze G, Rett K, Mehnert H (1985) Evidence for a substrate regulation of triglyceride lipolysis in human skeletal muscle. Horm Metab Res 17:471-475

30. Enoksson S, Degerman E, Hagstrom-Toft E, Large V, Arner P (1998) Various phosphodiesterase subtypes mediate the in vivo antilipolytic effect of insulin on adipose tissue and skeletal muscle in man. Diabetologia 41:560-568

31. Hagstrom-Toft E, Enoksson S, Moberg E, Bolinder J, Arner P (1998) beta-Adrenergic regulation of lipolysis and blood flow in human skeletal muscle in vivo. Am J Physiol 275:E909-E916

32. Basu A, Basu R, Shah P, Vella A, Rizza RA, Jensen MD (2001) Systemic and regional free fatty acid metabolism in type 2 diabetes. Am J Physiol Endocrinol Metab 280:E1000-E1006

33. Hickner RC, Racette SB, Binder EF, Fisher JS, Kohrt WM (1999) Suppression of whole body and regional lipolysis by insulin: effects of obesity and exercise. J Clin Endocrinol Metab 84:3886-3895

34. Jansson PA, Smith U, Lonnroth P (1990) Interstitial glycerol concentration measured by microdialysis in two subcutaneous regions in humans. Am J Physiol 258:E918-E922

35. Koutsari C, Jensen MD (2006) Thematic review series: patientoriented research. Free fatty acid metabolism in human obesity. J Lipid Res 47:1643-1650

36. Meek SE, Nair KS, Jensen MD (1999) Insulin regulation of regional free fatty acid metabolism. Diabetes 48:10-14

37. Haemmerle G, Moustafa T, Woelkart G et al (2011) ATGLmediated fat catabolism regulates cardiac mitochondrial function via PPAR-alpha and PGC-1. Nat Med 17:1076-1085

38. Schweiger M, Schreiber R, Haemmerle G et al (2006) Adipose triglyceride lipase and hormone-sensitive lipase are the major enzymes in adipose tissue triacylglycerol catabolism. J Biol Chem 281:40236-40241

39. Turinsky J, O'Sullivan DM, Bayly BP (1990) 1,2-Diacylglycerol and ceramide levels in insulin-resistant tissues of the rat in vivo. J Biol Chem 265:16880-16885 
40. Boni LT, Rando RR (1985) The nature of protein kinase C activation by physically defined phospholipid vesicles and diacylglycerols. J Biol Chem 260:10819-10825

41. Eichmann TO, Kumari M, Haas JT et al (2012) Studies on the substrate and stereo/regioselectivity of adipose triglyceride lipase, hormone-sensitive lipase, and diacylglycerol-O-acyltransferases. J Biol Chem 287:41116-41457

42. Montell E, Turini M, Marotta M et al (2001) DAG accumulation from saturated fatty acids desensitizes insulin stimulation of glucose uptake in muscle cells. Am J Physiol Endocrinol Metab 280:E229-E237

43. van Hees AM, Jans A, Hul GB, Roche HM, Saris WH, Blaak EE (2011) Skeletal muscle fatty acid handling in insulin resistant men. Obesity (Silver Spring) 19:1350-1359

44. Yu HY, Inoguchi T, Kakimoto M et al (2001) Saturated nonesterified fatty acids stimulate de novo diacylglycerol synthesis and protein kinase c activity in cultured aortic smooth muscle cells. Diabetologia 44:614-620

45. Jocken JW, Goossens GH, van Hees AM et al (2008) Effect of beta-adrenergic stimulation on whole-body and abdominal subcutaneous adipose tissue lipolysis in lean and obese men. Diabetologia 51:320-327

46. Guo Z, Jensen MD (1999) Blood glycerol is an important precursor for intramuscular triacylglycerol synthesis. J Biol Chem 274: 23702-23706

47. Sjostrand M, Holmang A, Lonnroth P (1999) Measurement of interstitial insulin in human muscle. Am J Physiol 276: E151-E154

48. Jansson PA, Fowelin JP, von Schenck HP, Smith UP, Lonnroth PN (1993) Measurement by microdialysis of the insulin concentration in subcutaneous interstitial fluid. Importance of the endothelial barrier for insulin. Diabetes 42:1469-1473

49. Sjostrand M, Gudbjornsdottir S, Holmang A, Lonn L, Strindberg L, Lonnroth P (2002) Delayed transcapillary transport of insulin to muscle interstitial fluid in obese subjects. Diabetes 51:27422748

50. Sjostrand M, Holmang A, Strindberg L, Lonnroth P (2000) Estimations of muscle interstitial insulin, glucose, and lactate in type 2 diabetic subjects. Am J Physiol Endocrinol Metab 279: E1097-E1103 